\title{
EFEITOS DO TRABALHO SOBRE O ADOECIMENTO ENTRE AGENTES CO- MUNITÁRIOS DE SAÚDE - UMA REVISÃO DE LITERATURA
}

\section{EFFECTS OF WORK ON SICKNESS AMONG COMMUNITY HEALTH AGENTS - A LITERA- TURE REVIEW}

\author{
Ladine Teixeira Santos ${ }^{\mathrm{a}^{*}}$, Fernanda de Oliveira Souza ${ }^{\mathrm{b}^{*}}$, Paloma de Souza Pinho Freitas ${ }^{\mathrm{c}^{*}}$ \\ dyne_saj@hotmail.comª, fernandasouza@ufrb.edu.br ${ }^{\mathrm{b}}$,paloma@ufrb.edu.br ${ }^{\mathrm{c}}$ \\ Universidade Federal do Recôncavo da Bahia*
}

\section{RESUMO}

Introdução: O trabalho dos Agentes Comunitários de Saúde (ACS) traz diversas novidades à atenção básica em saúde, destacando-se a obrigatoriedade de morarem e trabalharem na mesma comunidade. Objetivo: Compreender quais as efeitos do trabalho dos Agentes Comunitário de Saúde na saúde desses trabalhadores da atenção básica. Materiais e Método: Foi utilizada a estratégia de investigação da Revisão Integrativa da Literatura. Foram selecionados cinco artigos científicos, disponibilizados no portal de bases de dados Scientific Electronic Library Online (SciELO) utilizando descritores e palavras-chave como auxílio para a estratégia de busca. Resultados: A partir da análise dos textos, foi elaborada três categorias que apoiam as reflexões sobre os efeitos produzidos na saúde dos Agentes Comunitários de Saúde a partir do processo de trabalho, a saber: sobrecarga do trabalho; desgaste com a equipe de trabalho; ser trabalhador na comunidade que reside. Os resultados revelaram que estes profissionais que se dedicam a cuidar do outro, carecem de cuidar da própria saúde e suas condições de trabalho, muitas vezes, leva a um desgaste emocional. Conclusões: A pesquisa revelou que esses personagens, tão importantes na estrutura do serviço de saúde, como agentes modificadores do modelo assistencial vigente, não têm clareza do seu papel no sistema, sentem-se desvalorizados pelos gestores e pela comunidade. Isso exige que sejam implementadas políticas públicas que possam melhor avaliar o trabalho real desenvolvido pelos ACS e, a partir de um amplo diagnóstico, implementar ações que deem condições para que esses trabalhadores cumpram adequadamente sua função no Sistema Único de Saúde.

Palavras-chave: Agente Comunitários de Saúde; gestão em saúde; saúde do trabalhador.

\section{ABSTRACT}

Introduction: The work of the Community Health Agents (CHA) brings several novelties to basic health care, emphasizing the obligation to live and work in the same community. Objective: To understand the effects of the work of the Community Health Agents on the health of these primary care workers. Materials and Methods: The research strategy of Integrative Literature Review was used. Five scientific articles were selected, available in the Scientific Electronic Library Online (SciELO) database portal using descriptors and keywords as an aid to the search strategy. Results: Based on the analysis of the texts, three categories have been elaborated that support the reflections on the health effects of the Community Health Agents from the work process, namely: overload of work; wear with the work team; be a worker in the community you reside in. The results revealed that these professionals who are dedicated to taking care of the other, need to take care of their own health and their conditions of their work often leads to emotional exhaustion. Conclusions: The research revealed that these characters, who are so important in the structure of the health service, as modifying agents of the current care model, are not clear about their role in the system, they feel devalued by managers and the community. This requires that public policies be implemented that can better evaluate the actual work developed by the ACS and, based on a broad diagnosis, implement actions that enable these workers to adequately fulfill their role in the Unified Health System.

Keywords: Community Health Agents; health management; Worker's health. 


\section{Introdução}

A criação e implantação do Sistema Único de Saúde (SUS) representaram reformas sociais importantes no Brasil (FERREIRA, 2001) ${ }^{1}$. O SUS universalizou o acesso gratuito à saúde, ampliando a atenção básica, com ações voltadas para a promoção da saúde, a prevenção de agravos, o tratamento e a reabilitação. Com a preocupação de melhorar o atendimento, foram criados dois programas voltados para as ações referentes à atenção básica: Programa de Saúde da Família (PSF) e o Programa de Agentes Comunitários de Saúde (PACS).

Neste novo cenário, surgem atores importantes no processo de mudança do modelo biomédico hegemônico: os Agentes Comunitários de Saúde (ACS). Para Jardim (2009) $)^{2}$ o trabalho dos ACS traz diversas novidades à atenção básica em saúde, destacando-se o fato da obrigatoriedade dos agentes morarem e trabalharem na mesma comunidade. Nesse contexto, o agente passa a ter um duplo papel: o de ser simultaneamente agente e sujeito das ações em saúde. Segundo o autor a dupla inserção pode ocasionar uma porosidade entre trabalhar e o viver na comunidade. Nesse sentido, o trabalho do agente, da maneira como está organizado, pode ser uma fonte de sofrimento psíquico para esse trabalhador, podendo esse sofrimento torna-se patogênico.

Os ACS surgiram como personagens-chave na implantação das políticas voltadas para a reorientação do modelo de atenção em saúde, pois são potencialmente capazes de agregarem diversos conhecimentos em torno da questão do processo saúde-doença-cuidado, incorporando outros saberes além da perspectiva biomédica, tais como habilidade de interação cotidiana com as famílias e no reconhecimento de suas necessidades, sendo assim considerados elo entre serviço de saúde e comunidade (NUNES et al., 2002) ${ }^{3}$. A tabela 1 apresenta as principais atividades dos ACS.

Quadro 1: Atribuições dos Agente Comunitários de Saúde

I: Trabalhar com adscrição de indivíduos e famílias em base geográfica definida e cadastrar todas as pessoas de sua área, mantendo os dados atualizados no sistema de informação da Atenção Básica vigente, utilizando-os de forma sistemática, com apoio da equipe, para a análise da situação de saúde, considerando as características sociais, econômicas, culturais, demográficas e epidemiológicas do território, e priorizando as situações a serem acompanhadas no planejamento local

II: Utilizar instrumentos para a coleta de informações que apoiem no diagnóstico demográfico e sociocultural da comunidade

III: Registrar, para fins de planejamento e acompanhamento das ações de saúde, os dados de nascimentos, óbitos, doenças e outros agravos à saúde, garantido o sigilo ético

IV: Desenvolver ações que busquem a integração entre a equipe de saúde e a população adscrita à UBS, considerando as características e as finalidades do trabalho de acompanhamento de indivíduos e grupos sociais ou coletividades

V: Informar os usuários sobre as datas e horários de consultas e exames agendados

VI: - Participar dos processos de regulação a partir da Atenção Básica para acompanhamento das necessidades dos usuários no que diz respeito a agendamentos ou desistências de consultas e exames solicitados

VII: Exercer outras atribuições que lhes sejam atribuídas por legislação específica da categoria, ou outra normativa instituída pelo gestor federal, municipal ou do Distrito Federal

Fonte: Portaria ${ }^{\circ} 2.436$, DE 21 de setembro DE $2017^{4}$ 
Os ACS possuem um papel muito específico que os difere dos demais membros da equipe. Antes de tudo, são pessoas que convivem com a realidade e as práticas de saúde do bairro onde moram, já que um dos critérios para se tornar agente é residir no local onde irá atuar, portanto identificam-se com a cultura, linguagem e os costumes de sua própria comunidade (NUNES, 2002)3. Os ACS são, portanto, os mediadores ou elo entre a comunidade e os serviços de saúde, o que os torna referência na avaliação e articulação da saúde no Brasil.

De acordo com Nascimento $(2008)^{5}$ esse trabalho de mediação pode ser muito relevante para transformação do modelo assistencial, assumindo um caráter inovador e enfatizando a educação popular para mudança do modelo assistencial. Segundo o autor supracitado, o trabalho dos ACS requer um vínculo direto com a comunidade, sendo este fator de fundamental importância para o andamento das atividades. Desta forma, o trabalho dos ACS une dois universos culturais distintos: o científico e o popular, ajudando assim no trabalho de vigilância e na promoção da saúde.

Segundo Riquinho et al $(2017)^{6}$ outro elemento do dia a dia dos ACS que revela as dificuldades e a potência do seu trabalho é o fato de morar e trabalhar na comunidade. Enquanto os demais profissionais, geralmente encerram o turno de trabalho e vai embora, as ACS continuavam sendo solicitadas nas demandas de saúde e questionadas sobre a organização do serviço.

$\mathrm{Na}$ mesma direção, Nogueira et al. $(2000)^{7}$ afirmam que existem dois aspectos fundamentais na identidade profissional dos ACS: sua afinidade com a comunidade e a tendência para a ajuda solidária. $\mathrm{O}$ fato de o ACS ser da mesma comunidade em que trabalha, segundo o autor, contribuiria para a eficácia das ações de educação para saúde, pelo fato de haver compartilhamento social, cultural e linguístico, o que facilitaria na identificação de fatores responsáveis pelo surgimento das doenças e possibilitaria o desenvolvimento de estratégias mais eficientes em relação às recomendações médicas,

Desta forma, faz-se necessário compreender quais as efeitos do trabalho dos ACS na saúde desses trabalhadores da atenção básica? O objetivo desse trabalho foi identificar o perfil de morbidade dos ACS, conhecer as estratégias utilizadas pelos ACS para enfrentar os seu próprio adoecimento, e verificar ações existentes voltadas para os ACS para o enfrentamento do seu adoecimento. Para isso, foi realizada uma revisão integrativa da literatura no intuito de produzir conhecimento sobre essa população, a fim de suscitar a formulação de políticas públicas que visem à melhoria das condições de trabalho destes profissionais

\section{Método}

Nesta pesquisa foi realizada a estratégia de investigação da Revisão Integrativa de Literatura. Segundo Ercole et al $(2014)^{8}$ a Revisão Integrativa da literatura é um dos métodos que tem como finalidade sintetizar resultados obtidos em pesquisas sobre um tema ou questão, de maneira sistemática, ordenada e abrangente. É denominada integrativa porque fornece informações mais amplas sobre um assunto/problema, constituindo, assim, um corpo de conhecimento. Deste modo, o revisor/pesquisador pode elaborar uma revisão integrativa com diferentes finalidades, podendo ser direcionada para a definição de conceitos, revisão de teorias ou análise metodológica dos estudos incluídos de um tópico particular.

Esse método foi selecionado para a presente pesquisa devido à sua abrangência a estudo coletivos e pela capacidade de proporcionar o conhecimento minucioso e detalhado do objeto de estudo. A finalidade desse método é permitir que o pesquisador entre em contato com o que já foi produzido sobre seu tema de pesquisa.

A revisão integrativa acontece através de algumas etapas, a saber: formulação da pergunta, investigação na literatura, seleção dos critérios de inclusão e exclusão, definição das informações a serem extraídas, avaliação dos estudos, interpretação dos resultados e síntese do conhecimento (MENDES, 2008) 9 .

Esta pesquisa buscou em publicações sobre o objeto de estudo, dados que subsidiassem a questão norteadora: quais as implicações do trabalho dos ACS na saúde desses trabalhadores da atenção básica? Desta forma os sujeitos do estudo foram os ACS e a relação do seu trabalho com seu adoecimento. 
Para o presente estudo estabeleceu-se, para compor a amostra, um mínimo de 05 artigos de maior relevância publicados, nos últimos cinco anos, na temática pesquisada. A busca bibliográfica foi realizada utilizando-se os seguintes descritores na base de dados Scientific Electronic Library Online (SciELO): agente comunitário de saúde, condições de trabalho, adoecimento, esgotamento profissional. Foram selecionados apenas os artigos gratuitos, disponíveis na integra no período de 2013 a 2018. Estabeleceram-se como critérios de inclusão o exame dos títulos e sumários para remover os estudos irrelevantes para a pesquisa. A busca foi realizada em estudos referentes ao contexto brasileiro, divulgados em português. Os critérios utilizados para exclusão foram a remoção de registros duplicados.
A partir da análise dos textos, foi elaborado algumas categorias que apoiam as reflexões sobre as implicações do processo de trabalho dos Agentes Comunitários de Saúde em sua saúde. São elas: Sobrecarga do trabalho, Desgaste com a equipe de trabalho, Ser trabalhador na comunidade que reside.

\section{Resultados e Discussão}

Foram analisados cinco artigos entre os anos de 2013 a 2018, e os resultados estão expostos no quadro a seguir:

Quadro 2 - Descrição dos artigos localizados na base de dados

\begin{tabular}{|c|c|c|c|}
\hline Título do artigo & Autores & Principais Resultados & Conclusão \\
\hline $\begin{array}{l}\text { 1. Alegrias e tristezas } \\
\text { no cotidiano de trabalho } \\
\text { do agente comunitário } \\
\text { de saúde: cenários de } \\
\text { paixões e afetamentos. }\end{array}$ & $\begin{array}{l}\text { 2013. GALAVOTE, } \\
\text { Heletícia Scabelo; } \\
\text { FRANCO, Túlio } \\
\text { Batista; LIMA, Rita } \\
\text { de Cássia Duarte; } \\
\text { BELIZARIO, Antônio } \\
\text { Márcio }\end{array}$ & $\begin{array}{l}\text { Tristeza nos ACS é } \\
\text { gerada pela relação } \\
\text { com os profissionais } \\
\text { da equipe e a própria } \\
\text { gestão do trabalho. }\end{array}$ & $\begin{array}{l}\text { O estudo revela um } \\
\text { ACS múltiplo, exposto } \\
\text { às afecções das relações } \\
\text { que mantém, variando } \\
\text { entre o reconhecimento } \\
\text { e a submissão às lógicas } \\
\text { instituídas, resultando } \\
\text { em alegria e tristeza, } \\
\text { aumento e redução da } \\
\text { sua potência de agir, } \\
\text { respectivamente }\end{array}$ \\
\hline $\begin{array}{c}\text { 2. Afetividade e seus } \\
\text { sentidos no trabalho do } \\
\text { agente comunitário de } \\
\text { saúde }\end{array}$ & $\begin{array}{l}\text { 2015. MOURA, Raul } \\
\text { Franklin Sarabando de; } \\
\text { CASTRO e SILVA, } \\
\text { Carlos Roberto de. }\end{array}$ & $\begin{array}{c}\text { Organização do } \\
\text { trabalho gera sobrecarga } \\
\text { do trabalho, em } \\
\text { contrapartida, o } \\
\text { estabelecimento de } \\
\text { vínculos entre os } \\
\text { colegas de trabalho } \\
\text { fortalece o ACS. }\end{array}$ & $\begin{array}{l}\text { Os resultados apontam } \\
\text { a importância de } \\
\text { referências sobre } \\
\text { afetividade e amizade } \\
\text { para a compreensão das } \\
\text { práticas de cuidado e } \\
\text { organização do trabalho } \\
\text { em saúde. }\end{array}$ \\
\hline
\end{tabular}




\begin{tabular}{|c|c|c|c|}
\hline $\begin{array}{c}\text { 3. Percepções dos } \\
\text { Agentes Comunitário } \\
\text { de Saúde: contribuições } \\
\text { para a gestão em saúde }\end{array}$ & $\begin{array}{l}\text { 2016. SPERONI, } \\
\text { Katiane Sefrin; FRUET, } \\
\text { Isolina maria Alberto; } \\
\text { DALMOLIN, Graziele } \\
\text { de Lima; DE LIMA, } \\
\text { Suzinara Beatriz Soares. }\end{array}$ & $\begin{array}{l}\text { A falta de apoio da } \\
\text { gestão municipal, dos } \\
\text { outros membros da } \\
\text { equipe de saúde e da } \\
\text { própria comunidade } \\
\text { são geradores } \\
\text { de sentimentos } \\
\text { de insatisfação e } \\
\text { desmotivação no } \\
\text { trabalho. }\end{array}$ & $\begin{array}{l}\text { A pesquisa sinaliza } \\
\text { que, para os ACS, a } \\
\text { valorização do seu } \\
\text { trabalho é de extrema } \\
\text { importância, para que } \\
\text { se sintam motivados } \\
\text { para desenvolver } \\
\text { suas ações, através } \\
\text { da definição de suas } \\
\text { atribuições; mudanças } \\
\text { no processo de } \\
\text { trabalho; capacitações } \\
\text { e treinamentos e pelo } \\
\text { apoio dos outros } \\
\text { membros da equipe de } \\
\text { saúde e da gestão em } \\
\text { suas ações }\end{array}$ \\
\hline $\begin{array}{c}\text { 4. O agente comunitário } \\
\text { de saúde como morador, } \\
\text { trabalhador e usuário } \\
\text { em São Carlos, São } \\
\text { Paulo }\end{array}$ & $\begin{array}{l}\text { 2017. MENEGUSSI, } \\
\text { Juliana Morais; } \\
\text { OGATA, Márcia } \\
\text { Niituma; ROSALINI, } \\
\text { Maria Helena Pereira }\end{array}$ & $\begin{array}{l}\text { Há que se ater sobre } \\
\text { a dimensão do } \\
\text { sofrimento, pelo fato } \\
\text { de morar e trabalhar no } \\
\text { bairro. }\end{array}$ & $\begin{array}{c}\text { O ACS precisa ser } \\
\text { compreendido na } \\
\text { singularidade que a } \\
\text { profissão apresenta, } \\
\text { proporcionando o } \\
\text { fortalecimento pessoal e } \\
\text { profissional cotidiano. }\end{array}$ \\
\hline $\begin{array}{l}\text { 5. O cotidiano de } \\
\text { trabalho do agente } \\
\text { comunitário de saúde: } \\
\text { entre a dificuldade e a } \\
\text { potência. }\end{array}$ & $\begin{array}{l}\text { 2018. RIQUINHO, } \\
\text { Deise Lisboa; PELLIN, } \\
\text { Tinã Vianna; RAMOS } \\
\text { SILVEIRA, Maicon } \\
\text { Rodrigues; SANTOS, } \\
\text { Vilma Constância } \\
\text { Fioravante dos. }\end{array}$ & $\begin{array}{c}\text { O trabalho da ACS } \\
\text { está permeado pela } \\
\text { complexidade e pelo } \\
\text { desgaste emocional, } \\
\text { que é mais evidente, } \\
\text { justamente pelo fato } \\
\text { de ter uma inserção } \\
\text { diferente: a de } \\
\text { compartilhar uma rotina } \\
\text { de vida com as pessoas } \\
\text { e ao mesmo tempo ser } \\
\text { trabalhador da saúde no } \\
\text { local onde vive. }\end{array}$ & $\begin{array}{c}\text { Ao se levarem em } \\
\text { conta as interfaces } \\
\text { entre o trabalho real e o } \\
\text { prescrito, é inegável a } \\
\text { necessidade de diálogo } \\
\text { entre o controle social, } \\
\text { profissionais e gestores } \\
\text { para o enfrentamento } \\
\text { das situações geradoras } \\
\text { de sofrimento aos } \\
\text { usuários e profissionais. }\end{array}$ \\
\hline
\end{tabular}

Fonte: elaborado pela autora

\section{SOBRECARGA DO TRABALHO}

O ACS está exposto no dia a dia a diversas cargas de trabalho, a saber: físicas, psicológicas, químicas e mecânicas. Laurell e Noriega (1989) ${ }^{10}$ propõem uma nova proposta teórico-metodológica para compreender as relações entre os elementos biopsíquicos e o processo de trabalho em sua dimensão histórica, considerando a saúde do trabalhador. Essa conexão entre as condições de trabalho e os elementos da reprodução social dos trabalhadores, consiste no que Laurell e Noriega $(1989)^{10}$ denominaram de "nexo biopsíquico humano". Desta forma, apresentam conceitos de 
"cargas de trabalho" e "processos de desgaste" aos quais estariam sujeitos os trabalhadores.

O conceito de "cargas de trabalho" é definido por Laurell e Noriega (1989) ${ }^{10}$ como elementos presentes no processo de trabalho que interagem entre si e o corpo do trabalhador, gerando desgaste, compreendido como perda da capacidade potencial e ou efetiva, corporal e psíquica.

O fator sobrecarga de trabalho aparece na maioria do textos analisados, sendo citado em quatro artigos. Os autores trazem como motivos geradores de sobrecarga do trabalho os ACS terem que marcar visitas na Unidade de Saúde, essa atribuição é percebida como desgastante por eles (MOURA e CASTRO e SILVA, 2015) ${ }^{11}$; o desvio de função, ou seja, ter que fazer outras tarefas como as atividades burocráticas na unidade de saúde, podem repercutir de forma negativa no fazer profissional do ACS, como apontam Speroni et al (2016) ${ }^{12}$. Menegussi, Ogata e Rosalini (2014) ${ }^{13}$ também ressaltam que a justaposição de atividades à rotina administrativa presente nas Unidades de Saúde da Família é motivo dessa sobrecarga. Riquinho et al $(2018)^{6}$ apresentam a questão do desvio de função, devido ao ACS estarem assumindo atividades que se distanciam de seu lócus de intervenção e o número reduzido de profissionais e excesso de demanda serem apontados pelos ACS do estudo como desencadeantes da sobrecarga.

Na mesma direção dos artigos publicados, Costa et al. (2012) ${ }^{14}$ ressaltam que os ACS se sentem sobrecarregados, uma vez que, além de suas atribuições e um número elevado de famílias que necessitam acompanhar, ainda exercem outras funções (atividades administrativas, recepção, auxiliar de serviços gerais, entre outros). Costa et al. (2012) $)^{14}$ advertem para a necessidade dos gestores avaliarem a inclusão de auxiliares administrativos na ESF; a diminuição de famílias por ACS e investirem em capacitações e educação permanente. De acordo com os autores, o modo de organização do processo de trabalho do ACS pode ocasionar desgaste, que pode ser potencializado quando não há o reconhecimento dos gestores.

Wai $(2007)^{15}$, aponta que compartilhar os problemas com a equipe e outros profissionais serve como uma das estratégias de enfrentamento frente à sobrecarga do trabalho. Contudo, apesar dos ACS serem considerados como uma "ponte" entre a população e a equipe de saúde (FERNANDES, 1992) ${ }^{16}$ o relacionamento com os demais membros da equipe apareceu na revisão como fator gerador de adoecimento, como será explanado na próxima categoria.

\section{DESGASTE COM A EQUIPE DE TRABALHO}

O desgaste é um processo de adaptação que Laurell e Noriega (1989) ${ }^{10}$ compreendem como perda da capacidade potencial e/ou efetiva, biológica e psíquica. O desgaste como categoria conectada com o de carga, refere-se a um conjunto dos complexos processos psíquicos e biológicos que desgastam as capacidades vitais do trabalhador, consumindo assim, sua força de trabalho.

Em relação as implicações em desenvolver um trabalho em equipe, os resultados demonstram que os ACS experienciam relações distintas em seu processo de trabalho. Galavote et al $(2013)^{17}$ evidenciaram que o ACS é considerado, pela equipe, como uma "página em branco", de forma que os conhecimentos que ele tem de suas experiências não encontram lugar em um espaço de supremacia do saber biomédico.

$\mathrm{Na}$ mesma direção, Nunes et al. $(2002)^{3}$ analisam o processo de construção de identidade dos ACS a partir de sua inserção na equipe do PSF e da interação com os moradores dos bairros onde atuam. A partir dessa análise, demonstrou-se que o pertencer à equipe pode ser um fator gerador de ansiedade, quando eles comparam o seu conhecimento com o de outros profissionais da equipe. Isso porque o ACS não possuem um saber específico que demarque um rol de atribuições e um espaço que lhe confira identidade em relação aos demais trabalhadores da equipe.

Corroborando com os autores supracitados, Riquinho et al $(2018)^{6}$ afirmam que a desvalorização da equipe no que diz respeito ao trabalho das ACS pode estar atrelada ao saber informal que eles detêm. É nessa perspectiva que o trabalho do ACS acaba sendo desvalorizado. Para Menegussi, Ogata e Rosalini $(2014)^{13}$ o saber do ACS é subjugado o que demonstra a existência de equipes que não atuam de acordo com o que está previsto para a Estratégia Saúde da Família, o que reflete em atendimentos fragmentados e 
desmotivadores.

Em contrapartida, Moura e Silva $(2015)^{11}$ ressaltam, que o vínculo entre os próprios ACS pode fortalecer seu trabalho. De acordo os autores a proximidade e a cooperação com outros trabalhadores proporcionam sintonia ao serviço, harmonizam as diferenças entre os profissionais.

Conforme Croccia (2009) ${ }^{18}$, a função do ACS foi pensada e criada para o desenvolvimento de ações de promoção da saúde e prevenção de doenças, por meio de atendimentos nos domicílios e na comunidade, mediante ações educativas individuais ou coletivas, desenvolvidas de acordo com as diretrizes do SUS. Ressalta, ainda, que, em suas atribuições, os ACS possuem elementos para: conscientizar a população dos riscos e agravos que podem afetá-los; educar a população para ações em saúde (promoção da saúde e prevenção de doenças); estimular a participação social nas questões de saúde; auxiliar no funcionamento das ações realizadas pela equipe de saúde.

Lopes et al (2012) ${ }^{19}$, apontam o sofrimento devido ao desconhecimento das funções dos ACS pela comunidade e pela equipe de trabalho, gerando excesso de atribuições, refletindo negativamente no reconhecimento profissional. Conforme Tomaz $(2002)^{20}$, por falta de uma clara delimitação de suas atribuições, o papel do ACS tem sido distorcido. Segundo o autor, as atribuições dos ACS devem ser claramente estabelecidas e articuladas com as atividades desenvolvidas pelos outros profissionais que fazem parte de uma equipe de saúde.

Freitas et al. (2007) $)^{21}$ apontam como essencial incentivar e realizar capacitações com os ACS, ressaltando a importância de treinamento, supervisão frequente e avaliação contínua e qualitativa do serviço prestado à comunidade. Dessa forma, seria possível fornecer aos ACS conhecimentos acerca do processo saúde-doença em todas as suas dimensões. Na mesma direção, Duarte et al. (2007) $)^{22}$ afirma que os ACS devem ser capacitados sobre todos os aspectos do processo saúde-doença, não apenas na dimensão do saber biomédico, mas incorporando outros saberes, a fim de favorecer o processo de interação dos ACS com a população e estimular a corresponsabilidade desta na melhoria de sua qualidade de vida e saúde. SER TRABALHADOR NA COMUNIDADE QUE RESIDE
Uma das premissas do Ministério da Saúde é de que o ACS resida na área da comunidade em que irá atuar (BRASIL, 2017) ${ }^{4}$, com o intuito de facilitar a articulação entre o serviço de saúde e a comunidade. Nos artigos pesquisados, aparecem as dificuldades e a potência do trabalho dos ACS pelo fato de morar e trabalhar na comunidade.

Speroni $(2016)^{12}$ relata a sobrecarga do trabalho pelo fato dos ACS residirem $\mathrm{e}$ trabalharem na comunidade. $\mathrm{O}$ grande vínculo com a comunidade gera muitas cobranças e falta de compreensão por parte dos moradores. Para Menegussi, Ogata e Rosalini, (2014) $)^{13}$, residir no local de trabalho pode não facilitar o desenvolvimento das atividades dos agentes, por ser alguém que sabe muito sobre a comunidade e seus moradores isso pode ser visto como uma interferência negativa.

Santos e David (2011) ${ }^{23}$ também ressaltam que o fato do ACS ser morador da comunidade e não se afastar do seu ambiente de trabalho pode resultar em estresse. Segundo os autores, os ACS acabam sendo o "para-raios" para as insatisfações da população em relação aos serviços públicos. $\mathrm{Na}$ mesma direção, Camelo; Galon; Marziale $(2012)^{24}$ afirmam que as pessoas confundem o trabalho que é público, com o espaço de viver e conviver, que é particular pela impossibilidade do ACS de se distanciar do ambiente em que trabalha por morar nele. O que gera medo e sensação de vulnerabilidade devido ao assédio das pessoas.

Contudo, o fato de trabalhar e morar na comunidade pode ser um fator facilitador do trabalho. Em Riquinho et al $(2018)^{6}$ está facilidade dar-se pela proximidade da casa e ao fato de não depender de transporte coletivo. Já Moura e Silva $(2015)^{11}$ afirma que a proximidade que o ACS sente diante da pessoa acompanhada permite a construção de bons encontros. O agente de saúde, não se torna um amigo, mas uma pessoa confiável, com que se pode contar.

Rios $(2007)^{25}$ aponta que muitos estudos realizados com os ACS vem demonstrando que essa é uma população susceptível ao sofrimento psíquico e estresse, devido a estar inserido num contexto que o autor nomeou como um "campo de batalha", uma batalha que o agente trava com a miséria, a doença, a ignorância, 
a violência, o desprezo pela vida humana e a morte. "A onipotência e a frustração permeiam a subjetividade de um agente social, que mantém profunda relação de pertença com seu espaço: o espaço em que vive é o mesmo onde atua, as pessoas da sua realidade social são as mesmas para quem dirige as suas ações de cuidado" (BACHILLI, 2008) ${ }^{26}$.

\section{Conclusões}

Esta pesquisa permitiu descrever as cargas de trabalho ao qual os ACS são submetidos e as estratégias utilizadas por eles para o enfrentamento do seu adoecimento. Os ACS são atores importantes para a consolidação na atenção básica, contudo, foi possível identificar através da literatura, que estes profissionais estão adoecendo e não foram encontradas ações para o enfrentamento dessa problemática.

As altas exigências impostas pelo trabalho; a falta de reconhecimento de seus esforços pela comunidade e pela gestão; o intenso envolvimento emocional com a população acaba gerando sobrecarga do trabalho e consequentemente, produz desgastes. Uma das dificuldades enfrentadas pelos ACS e apontada em alguns artigos, é o fato de residirem no mesmo bairro em que trabalham. Apesar de ser uma exigência para a inserção na profissão, essa premissa, a longo prazo, pode desenvolver sofrimentos de ordem emocional, que refletem no desenvolvimento do trabalho dos ACS e em sua qualidade de vida, pois muitas vezes a população não sabe separar o profissional do morador do bairro no seu tempo livre.

A falta de reconhecimento profissional pela equipe e gestão em saúde gera nos ACS sentimentos de desmotivação, desvalorização, falta de comprometimento com o trabalho. O desconhecimento das funções do ACS por parte da própria equipe e também da comunidade; a valorização social do trabalho dos outros profissionais como do médico, em detrimento do ACS, provoca neste profissional, a experiência do fracasso e insatisfação.

Para aliviar as tensões do cotidiano do trabalho foram identificadas como estratégias de enfrentamento o vínculo entre os próprios ACS, o vínculo com a população atendida e compartilhar os problemas com a equipe e outros profissionais.

O sofrimento do ACS portanto, perpassa por diversos fatores como vistos nos artigos pesquisados. A partir dos resultados sugere-se que esse conhecimento acerca das condições de trabalho dos ACS possa fomentar políticas públicas que promovam saúde para esses profissionais da saúde, a fim de suscitar ações que despertem cuidado desses trabalhadores e gerem subsídios para a política de saúde do trabalhador, contando inclusive, com a participação desses profissionais na elaboração dessas políticas.

Os resultados apresentados nesta pesquisa apontam que a profissão de agente comunitário de saúde écrucial na busca de um SUS melhor, contudo precisa de maior cuidado por parte da gestão. É inegável a necessidade de diálogo entre os gestores de saúde e os ACS para o enfrentamento das situações que geram sofrimento aos profissionais, objetivando práticas que visem à melhoria do SUS e do processo de trabalho dos ACS.

Para trabalhos futuros, mostra-se importante que sejam realizadas pesquisas sobre a percepção do gestores de saúde sobre o cotidiano do trabalho dos ACS, objetivando a melhoria dos fatores condicionantes à saúde, a fim de aprimorar as políticas de saúde para esta categoria profissional. Dessa forma, visa abrir caminhos para que novas pesquisas sejam realizadas para contribuir no aprimoramento das ações de gestão e no processo de trabalho dos ACS.

\section{Referências}

1. Ferreira SMG. Principais sistemas de informação de abrangência nacional. In. SUS - O que você precisa saber sobre o Sistema Único de Saúde. Associação Paulista de Medicina. v. II $1^{a}$ edição, São Paulo, 2001.

2. Jardim TA, Lancman S. Aspectos subjetivos do morar e trabalhar na mesma comunidade: a realidade vivenciada pelo agente comunitário de saúde. Interface (Botucatu) 2009;13(28):123-135.

3. Nunes MO, TRAD LB, ALMEIDA BA, HOMEM CR, MELO MCIC. O agente comunitário de saúde: construção da identidade desse personagem híbrido e polifônico. Caderno de Saúde Pública. 2002;18(6):p.1639-1646.

4. Brasil. Ministério da Saúde. Portaria no. 2.436 de Setembro de 2017. Brasília: Diário oficial [da] República 
Federativa do Brasil, 2017.

5. Nascimento, CMB. Análise do cumprimento das práticas dos agentes comunitários de saúde em municípios da Região Metropolitana do Recife. Dissertação (mestrado). Fundação Oswaldo Cruz, Recife, 2008.

6. Riquinho, DL, Pellini Tv, Ramos DT, Silveira M, Santos, Vilma CF. O cotidiano de trabalho do agente comunitário de saúde: entre a dificuldade e a potência. Trabalho, Educação e Saúde, 2018; 16(1), 163-182. Epub 11 de dezembro de 2017.Disponivel em <https://dx.doi. org/10.1590/1981-7746-sol00086>.

7. Nogueira RP, Silva FB, Ramos ZVO. A vinculação institucional de um trabalhador sui generis: o Agente Comunitário da Saúde. Texto para discussão no 735 . Rio de Janeiro, 2000. Disponível em: <www.ipea.gov.br.>. Acesso em: 08 nov .2010.

8. Ercole FF, Melo LS, ALCOFORADO CLGC. Revisão Integrativa versus Revisão Sistemática. Rev Min Enferm. 2014 jan/mar; 18(1): 1-260

9. Mendes KDS, Silveira RC de CP, Galvao CM. Revisão integrativa: método de pesquisa para a incorporação de evidências na saúde e na enfermagem. Texto contexto enferm. 2008;17(4): 758-764.

10. Laurell AC, Noriega M. Processo de produção e saúde: trabalho e desgaste operário. São Paulo: Cebes - Hucitec, 1989.

11. Moura RFS, Silva CRC. Afetividade e seus sentidos no trabalho do agente comunitário de saúde Physis Revista de Saúde Coletiva[online]. 2015;.25(3):993-1010.

12. Speroni K S, FRUET I M A, DALMOLIN G de Lima, DE LIMA S B S. Percepções dos agentes comunitários de saúde: contribuições para a gestão em saúde. Rev Cuid [online]. 2016;7(2):1325-1337.

13. Menegussi JM, Ogata, M N, Rosalini MHP. O agente comunitário de saúde como morador, trabalhador e usuário em São Carlos, São Paulo. Trab. educ. saúde [online]. 2014;12(1):87-106.

14. Costa MC et al. Processo de trabalho dos agentes comunitários de saúde: possibilidades e limites. Rev. Gaúcha Enferm, 2012; 33(3):134-140.

15. Wai MFP, Carvalho AMP. O trabalho do agente comunitário de saúde: fatores de sobrecarga e estratégias de enfrentamento. Rev. Enferm, 2007; 17(4): 563-568.

16. Fernandes JCL. Agentes de saúde em comunidades urbanas. Cad. Saúde Pública. 1992;.8(2):134-139.

17. Galavote HS, Franco TB, Lima, RCD, Belizario AM. Alegrias e tristezas no cotidiano de trabalho do agente comunitário de saúde: cenários de paixões e afetamentos. Interface (Botucatu) [online]. 2013;.17(46):575-586

18. Croccia M A. representação do "trabalho" na vida do agente comunitário de saúde. Dissertação (mestrado). Universidade de São Paulo, São Paulo, 2009

19. .Lopes, DMQ et al. Agentes Comunitários de Saúde e as vivências de prazer - sofrimento no trabalho: estudo qualitativo. Rev. esc. enferm. USP [online]. 2012;46(3):633-640.

20. Tomaz JBC. O agente comunitário de saúde não deve ser um "super-herói". Interface - Comunicação, Saúde, Educação, 2002; 6(10):75-94.

21. Freitas AC, Silva LCP, Jesus MB, Kumanaya MF, Silva GTR. Desvelando a vivência de uma equipe multiprofissional de residentes em Saúde da Família com o Agente Comunitário de Saúde. Revista APS, 2007;10(2):143-55

22. Duarte LR., Silva DSJR, Cardoso SH. Construindo um programa de educação com agentes comunitários de saúde. Interface- Comunicação, Saúde, Educação, 2007;11(23)439-47.

23. Santos LFB, David, HMSL. Percepções do estresse no trabalho pelos agentes comunitários de saúde. Rev. Enferm, 2011;19(1):52-57.

24. Camelo SHH, Galon T, Marziale MHP. Formas de adoecimento pelo trabalho dos agentes comunitários de saúde e estratégias de gerenciamento. Rev. enferm., 2012;20(1):661-667.

25. Rios IC. Rodas de conversa sobre o trabalho na rua: discutindo saúde mental. Physis v.17, n.2 Rio de Janeiro, 2007.

26. Bachilli R. G S A J, Spiri W C. A identidade do agente comunitário de saúde: uma abordagem fenomenológica. Ciência e saúde coletiva. 2008;13(1)51-60.

\section{Como citar este artigo:}

Santos LT, Souza FO, Freitas PSP. Efeitos do trabalho sobre o adoecimento entre agentes comunitários de saúde - uma revisão de literatura. Rev. Aten. Saúde. 2019; 17(61): 105-113. 